\title{
Experimental Study of Egress Selection Behavior Between Stairs and Elevators During High-Rise Building Evacuation
}

\author{
Ning Ding, School of Criminal Investigation and Counterterror, People's Public \\ Security University of China, Beijing 100038, People's Republic of China \\ Hui Zhang, Tao Chen*, Institute of Public Safety Research/Department of \\ Engineering Physics, Tsinghua University, Beijing, People's Republic of \\ China
}

Received: 4 May 2016/Accepted: 8 February 2019

\begin{abstract}
How do evacuees behave and what factors influence their egress selection behavior of stairs or an elevator during a high-rise building evacuation? These issues remain unclear given a paucity of research. In this paper, a series of experiments and questionnaires with 45 participants were carried out to examine the effects of non-irritant smoke and participants' knowledge of evacuation procedures (especially elevator evacuation). After each experiment, participants were asked to respond to a questionnaire. The results of evacuation times for the elevator versus stairs, the proportion of elevator users, elevator wait times, and redirect behaviors are analyzed and discussed. In experiment $1,26.7 \%$ of 45 participants chose the elevator. In experiment 2 , non-irritant smoke was released, and the proportion of participants who used the elevator decreased to $24.4 \%$ of 45 participants. Before experiment 3 , we shared information about the evacuation (i.e., an explanation of evacuation procedures and elevator evacuation experience) with the participants, after which elevator use increased to $40 \%$ of 45 participants. As a result, we found that non-irritant smoke and knowledge of evacuations affected evacuees' behavior; however, the gap between the proportions of participants who reportedly preferred to use the elevator and who actually used the elevator was large. According to the questionnaire, the proportion of participants who wanted to use the elevator was $55.6 \%$. Moreover, elevator overload, physical fatigue, and social bonds were observed in our experiments. In conclusion, several suggestions are given to building designers, and basic data (such as evacuation times and proportion of stairs or elevator use) offer insight for building safety engineers in designing evacuation strategies incorporating stairs and elevators.
\end{abstract}

Keywords: Egress selection behavior, Elevator evacuation, Experiments, High-rise building

\section{Introduction}

In a high-rise building evacuation, how will evacuees behave when they have the option of using either stairs or an elevator? In countries such as the United Kingdom, Australia, China, and the United States, fire-proof elevators are used during

\footnotetext{
* Correspondence should be addressed to: Tao Chen, E-mail: chentao.a@tsinghua.edu.cn
} 
evacuations according to building codes [1-4], and the combined use of stairs and elevators can expedite high-rise building evacuations compared to evacuation by stairs alone [5, 6, 41, 42]. When designing an evacuation strategy including the use of stairs and elevators, evacuees are always assumed to be compliant [5]; it is expected they will wait for an elevator for as long as required. However, in reality, how many evacuees actually use elevators? How long will they wait, and under what conditions? What factors influence their decisions and behaviors? [39, 41] Answering these questions will prove helpful in improving evacuation strategies incorporating stairs and elevators.

Many factors $[6,7,28]$ may influence evacuees' decisions and behaviors, two of which are examined in this paper (other factors will be tested in our future work): (1) non-irritant smoke; and (2) knowledge of evacuation procedures (e.g., education or explanation, training, and previous elevator evacuation experience). When people are exposed to conditions with non-irritant smoke and low visibility, their psychological response to encountering smoke (e.g. risk perception, elevated motivation/anxiety) may influence their decision-making during evacuations $[10,11]$. People also become anxious and perceive risk differently after waiting [43]. Furthermore, evacuees may feel calmer if they possess more knowledge of or experience with evacuations in emergency situations, which prepares them to make decisions rather than follow others [12]. This paper aims to address the aforementioned issues through the performance of experiments.

In this paper, relevant research studies are presented in Sect. 2. Three experiments (experiment 1, 2, and 3) are detailed in Sect. 3. Forty-five undergraduate students participated in the experiments on the 10th floor of a high-rise building, and the process was recorded using surveillance cameras. In experiment 1, participants could use stairs and elevators to evacuate. To study how non-irritant smoke influences participants' decisions and behaviors, harmless non-irritant smoke was released in experiment 2. After experiment 2, we explained the experiments to the participants so they understood the situation. For example, they were told the building layout and ideal evacuation time when using elevators. Then, in experiment 3, participants evacuated the building under non-irritant smoke conditions. After each experiment, participants were asked to complete a questionnaire; survey responses revealed information about participants' psychological state that was not apparent from video records.

The results of these experiments are presented in Sect. 4. After analysis of the data, we found that non-irritant smoke has little impact on evacuees' behavior, whereas knowledge of evacuation influences evacuees' behavior and their choice to using an elevator or the stairs. Several interesting phenomena, such as the existence of leaders and followers, social bonds, crowding, and hesitation, were also observed in these experiments. Finally, the results of our experiments are compared to those of other studies $[6,7]$. 


\section{Liferature Review}

\subsection{Combined Use of Elevators and Stairs}

The conventional notion that elevators cannot be used during fire evacuations is a key issue given the need to ensure fast and effective ways to evacuate high-rise buildings [18]. In particular, the utilization of evacuation elevators has been widely recommended because it is not easy for individuals with disabilities to use stairs to evacuate $[9,29]$. In several previous evacuations, elevators were used to assist in the rapid egress of high-rises [13-17]. As a result, building codes in a few countries have stated the feasibility of using evacuation elevators in high-rise evacuations [1-4].The combined use of stairs and elevators can accelerate high-rise building evacuation compared to evacuating via stairs alone [9]. Many experiments have been carried out to study human behavior in corridors [32, 33], such as route choice behavior [34] and the generation and impact of bottlenecks [3537]. However, little research has investigated the combined use of elevators and stairs, and those that did highlighted evacuees' behavior [5-7, 18], which can influence evacuation efficiency. The committee of the American Society for Mechanical Engineers [19] has paid particular attention to evacuee behavior [20, 21]. As a result, the design of a stair and elevator evacuation strategy [40] should consider not only the issues of designing stairs [22, 23, 31] and evacuation elevators [24, 25] but also evacuee behavior. For example, how many evacuees will actually use elevators during an evacuation? How long will they wait for an elevator to arrive [39], and under what conditions? These issues have been investigated via online surveys or questionnaires in several studies [5-7], but participants' answers only represent what they plan to do rather than how they would actually behave. As a result, experiments must be carried out to collect evacuees' behavioral data.

\subsection{Factors Affecting the Choice Between Stairs and Elevators}

To improve building evacuation strategies using both stairs and elevators, planners should understand not only evacuee behavior but also the factors that influence it. According to previous studies, many factors [6] affect how evacuees behave, such as their psychological state (relative to the extent of an emergency), floor levels, and knowledge of evacuation procedures (building layout, average evacuation time, evacuation elevator operation speed, etc.). As the floor level rises, the proportion of evacuees using elevators becomes larger as determined by previous studies [5-7] and our questionnaires. The psychological state of the evacuating population is also affected by the evacuation environment, such as the presence of smoke. Harmless non-irritant smoke is an effective and safe way to enhance perceived pressure, etc. When people move around in non-irritant smoke conditions where visibility is low, their increasing anxiety influences their evacuation decisions $[10,11]$. Hence, this is considered a useful proxy for real smoke in an experiment. Knowledge of evacuation procedures is also an important factor because most elevators around the world are not allowed to be used during evacuations, and all building occupants are aware that elevators cannot be used in a fire event 
[44]. As a result, experiments are necessary to explore the actual influence of nonirritant smoke and knowledge of evacuations on evacuees' behavior.

\section{Experiments}

In this section, the building layout is introduced in Sect. 3.1. The formal experimental procedure is explained in Sect. 3.2.

\subsection{Building Layout}

Experiments were carried out in the Liuqing building at Tsinghua University, Beijing, China. It is an office building with 11 floors (the first floor is the lobby), and participants started to evacuate from Room 1 on the 10th floor (height: $35.8 \mathrm{~m}$ ). As shown in Fig. 1, there are two staircases and two elevators in the building, and the elevator room is connected by one of two staircases. To avoid issues with elevator scheduling, one of the two cars was shut down, and occupants on other floors were not allowed to use elevators during the experiments. The experiment participants were allowed to use only one of the elevators (other elevators were not available to prevent elevator scheduling from influencing the experiment). The elevator position and direction were shown on the elevator electronic display board, and the elevator car, elevator room, and stair structures appear in Fig. 2.

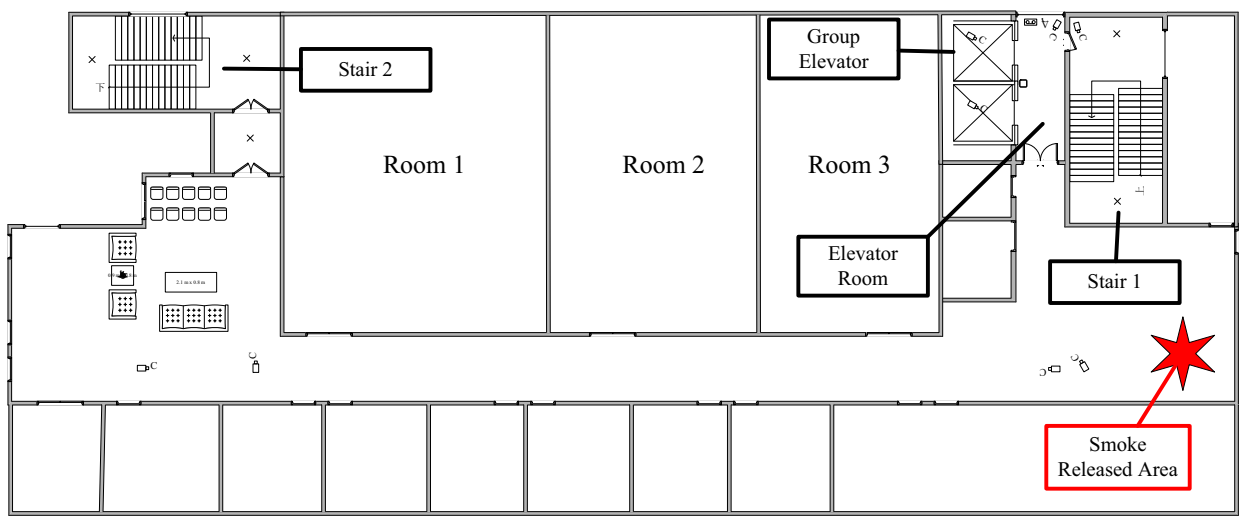

Figure 1. Building layout.
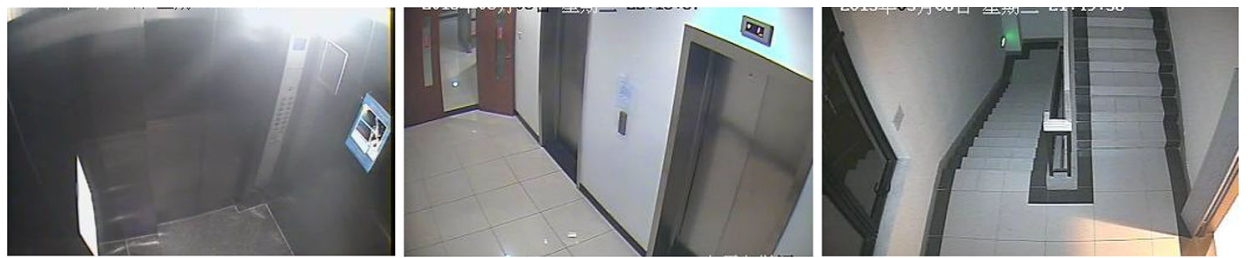

Figure 2. Car, elevator room and stair structure. 
Generally, although the capacity of each car is limited to 13 persons or $1000 \mathrm{~kg}$ total weight, one car cannot hold more than 13 people because passengers' cumulative weight routinely exceeds $1000 \mathrm{~kg}$. In the elevator, weight sensors are used to detect whether the elevator is overloaded, and an alarm will sound if it is. It took $27 \mathrm{~s}$ for the elevator to travel directly from the 10th floor to the 1st floor, not including wait time and the time it took for the door to open and close. Stair 1 connects with the elevator room. All the evacuees were only allowed to use these stairs so the authors could study occupants' behavior when combining elevator and stair use in the event of an evacuation (one elevator car and Stair 1). In summary, evacuees started in Room 1/Floor 10, when they arrived at the elevator room on Floor 10, they had to choose between Stair 1 and Elevator. When they reached level 1 , the experiment ended.

\subsection{Experimental Procedure}

Forty-five undergraduate students at Tsinghua University were invited to participate in the following experiments. The participants were majoring in nuclear physics, and they were not involved in our research project in any capacity; thus, they had no prior knowledge of the building layout or any previous elevator evacuation experience. Before the experiments, each participant completed a questionnaire including his or her basic information (discussed in Sect. 4.1) and had never before used elevators during an evacuation. The participants gathered in Room 1 on the 10th floor when they started to evacuate. After being told the elevators were safe, they were also informed that only one stair and one elevator could be used in these experiments. The elevator's initial position was on the 1st floor.

We hypothesized that non-irritant smoke and knowledge of evacuations would influence evacuees' egress selection behavior. Non-irritant smoke was released into the corridor as shown in Fig. 1. The basic assumptions of the experiments were (1) the evacuation experiments approximated real evacuation conditions; (2) the elevators in the experimental building could be used as evacuation elevators; (3) in addition to the first two factors, other factors were fixed in the three experiments - notably, most of the elevator room could not be infiltrated by smoke because of the pressurized system. (If elevators are used, the building should have a pressurized system.)

To test how non-irritant smoke and knowledge of evacuations influence evacuees' behavior. In experiment 1, 2 and 3, participants were told they should evacuate after the alarm sounds. Evacuees then had to decide whether to use the stairs or the elevator during the evacuation. Experiments 2 and 3 were conducted under non-irritant smoke conditions, where harmless non-irritant smoke was released by a cold, non-irritant smoke generator near the elevator room (see Fig. 1) on the 10th floor, and the participants did not know they would encounter the smoke. Experiment 2 was used to test the influence of non-irritant smoke on evacuees' decisions to use the stairs or the elevator. In experiment 3, people were still in the non-irritant smoke condition, but 5 min before the experiment, the following was explained: (1) the building layout; (2) The time to open and close the door of the elevator (TOC for short) of the elevator was about $27 \mathrm{~s}$ (not including wait time), 
and average duration when using stairs to evacuate was about $90 \mathrm{~s}$; and (3) if the elevator is overloaded, it cannot move. This was a deliberate attempt to ensure the participants' knowledge of what might be expected. After each experiment, participants had half an hour to take a rest and drink some water.

\section{Results and Discussion}

The questionnaire results are discussed in Sect. 4.1. The results of experiments 1, 2 , and 3 are presented in Sects. 4.2, 4.3, 4.4, respectively. Some evacuation phenomena are discussed in Sect. 4.6, where the experimental results are also compared. Limitations of our experiments are discussed in Sect. 4.7.

\subsection{Results of Questionnaires}

The questionnaires contained four sub-sections: questionnaire 0-3. Questionnaire 0 was used to collect evacuees' basic information, such as age and gender (see Table 1). This questionnaire was collected a week before the experiments. Questionnaires 1-3 were distributed after experiments 1-3, respectively. As shown in Table 1, 38 participants were male. Participants' ages ranged from 17 to 23 , and most of them were not familiar with the exits in the Liuqing building. All participants reported preferring to use elevators under normal conditions.

Table 1 indicates that most participants were unfamiliar with the building exits. They often travelled up to the 10th floor or down from the 10th floor; hence, the 10th floor was chosen as the experimental floor. Most participants did not think they could use elevators during an evacuation, and only $4.4 \%$ of them stated they would want to use an elevator in that situation, mainly because they did not perceive elevators to be safe in the event of an emergency. When we explained it would be safe to use the elevator (given that it had suitable protection), most participants thought the key advantage of using the elevator over stairs was speed. As shown in Fig. 3, the percentage of evacuees who wanted to use the elevator increased $257 \%$ from the 5 th floor to the 10 th floor. If participants were on the 20 th floor, nearly $80 \%$ of them stated they would want to use the elevator. The participants in this survey were all young, able-bodied people, and we would expect the percentage of elderly population who would choose to use the elevator on a certain floor to be higher $[12,38]$. As demonstrated in Fig. 3, the percentage of evacuees willing to use an elevator on the 10th floor increased to $55.6 \%$ from the percentages recorded on lower floors; thus, the 10th floor was crucial to follow-up test.

Questionnaires 1-3 were given after experiments 1-3, respectively. These questionnaires focused on participants' psychological state; questions are listed in Table 2, Table 3, and Table 4. From the results of the questionnaire, it was evident that most participants felt anxious during experiment 1 , and 36 of the participants felt increasingly anxious when they were in non-irritant smoke conditions compared to not. Although non-irritant smoke was still generated in experiment 3,33 of the participants did not feel as anxious as in experiment 2. More than half of the participants believed that non-irritant smoke and knowledge of evacua- 


\section{Table 1}

Results of Questionnaire 0

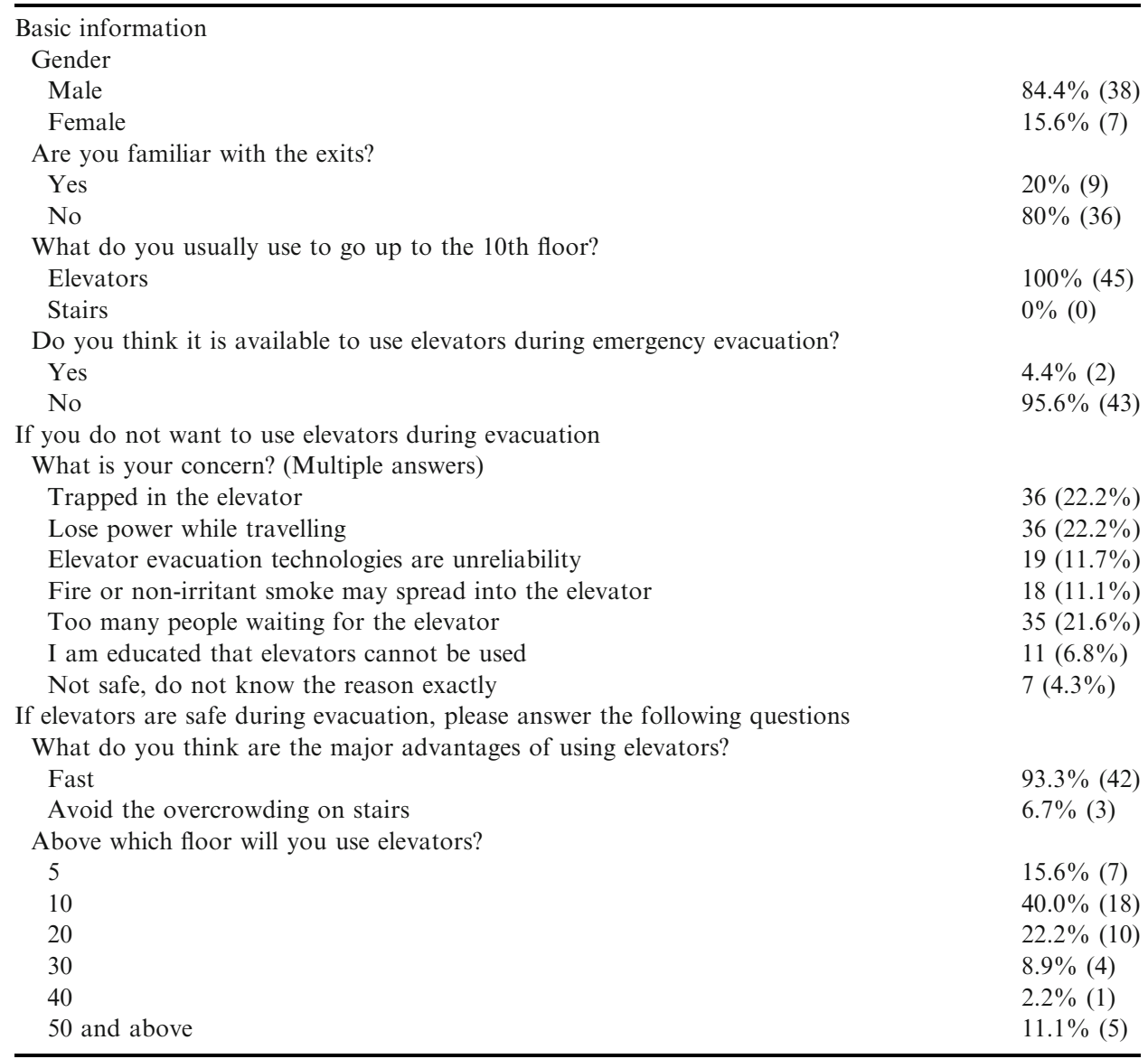

tion procedures influenced their decision to use stairs or the elevator during the experiments; results are discussed in detail in the next section. After the experiments, participants who used the stairs and reported feeling fatigued were questioned about on which floor they felt tired; these results appear in Fig. 4. Most of them felt fatigued after travelling down 7 (28 m vertically) to 8 floors (32 m vertically).

\subsection{Results of Experiment 1}

In experiment 1, participants could use either the stairs or elevator to evacuate. Photographs from experiment 1 are shown in Fig. 5. Figure 5a shows participants trying to enter the elevator car, and all of them started on Floor 10. In this experiment, 12 people used the elevator and 33 used the stairs. The elevator conducted two trips to pick up evacuees. During the first trip, 13 evacuees tried to enter the 


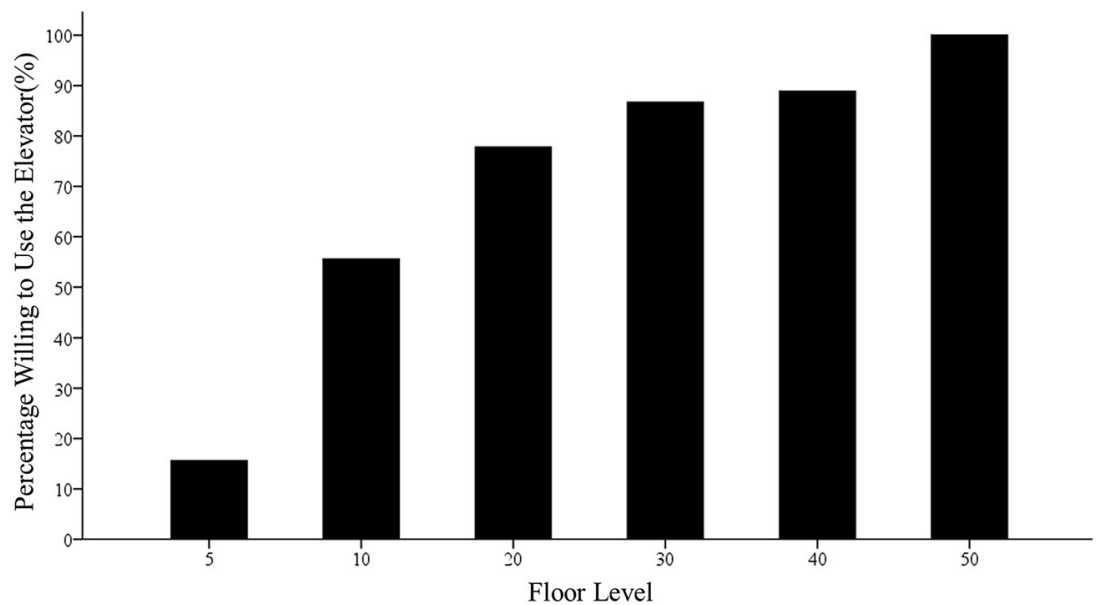

Figure 3. Cumulative percentages of participants who want to use elevators.

\section{Table 2}

\section{Results of Questionnaire 1}

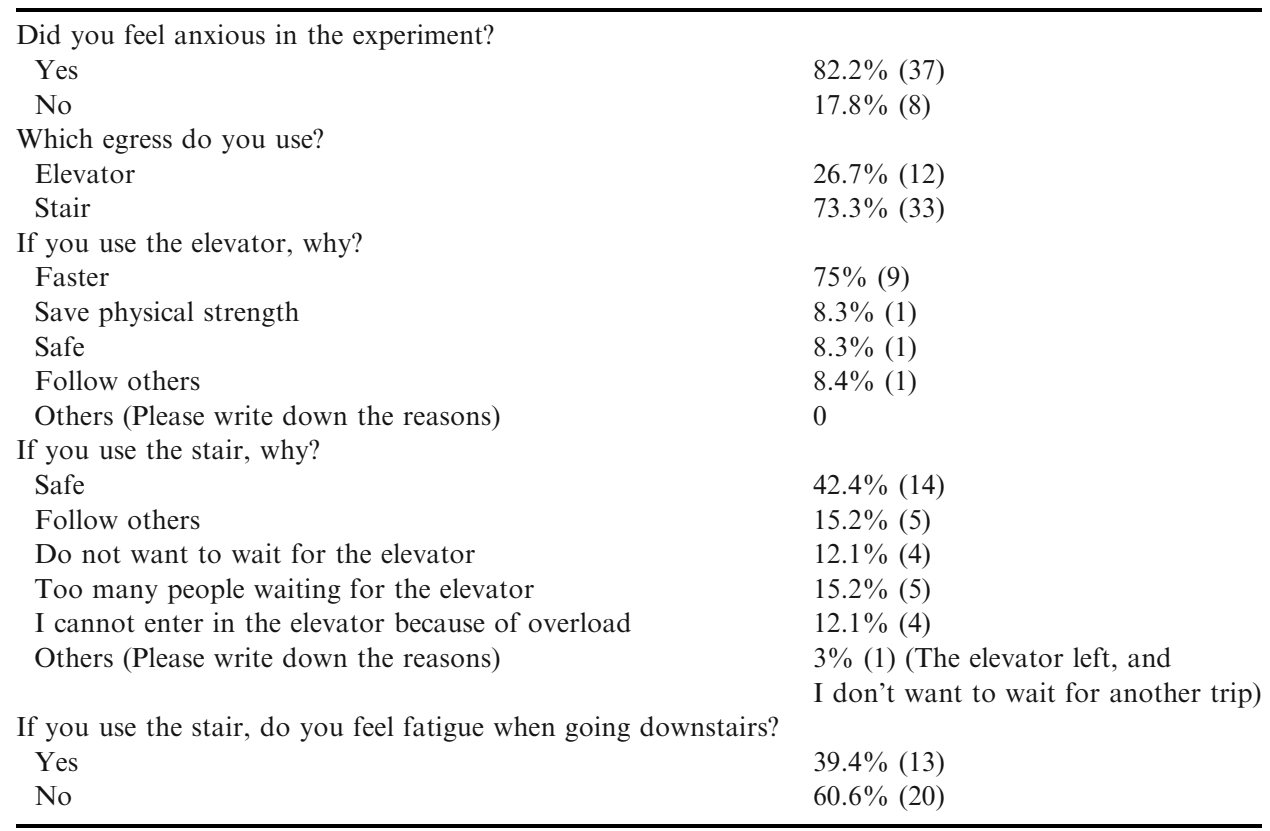




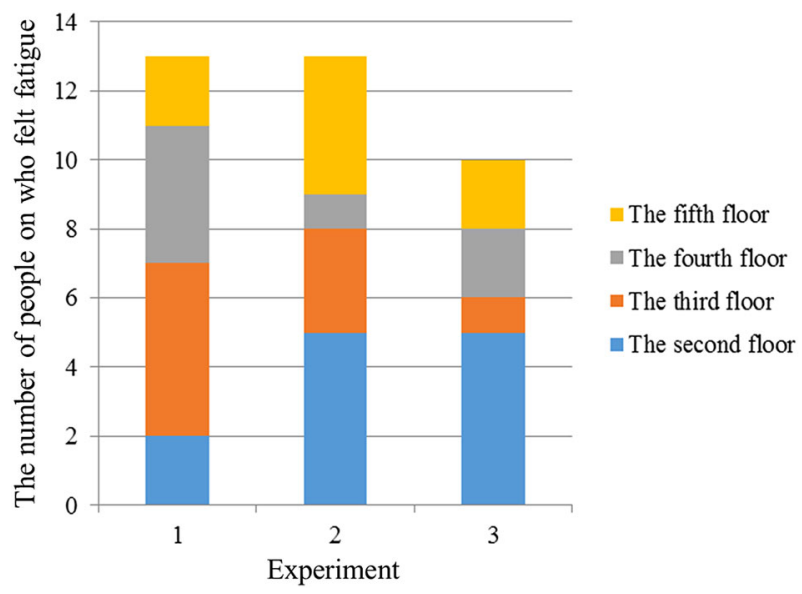

\section{Figure 4. The number of people on certain floors who felt fatigue in these experiments.}

car, but only 10 of them used the elevator for evacuation because the car was overloaded when all 15 evacuees were inside. Five evacuees exited the car, none of whom tried to wait for the elevator again. As shown in Fig. 5, several participants exited the car because it was overloaded. During the second trip, only two participants used the elevator. One of them descended to the 7th floor by the stair and waited for the elevator on the 7th floor (i.e., people may wait for elevators on other floors rather than their original floor). The wait times of the participants who tried to use the elevator are shown in Table 5. The average wait time for the second trip was much longer than that for the first trip, and only two participants waited for the second trip. When the elevator door opened for the first time, many evacuees looked into the car to determine whether they could use it. In this experiment, three evacuees decided to use the stairs.

The evacuation process began when the first participant entered the elevator room on the 10th floor until the last participant arrived at the elevator room on the 1st floor; results are shown in Fig. 6. The stair evacuation and elevator evacuation times for experiment 1 were $178 \mathrm{~s}$ and $201 \mathrm{~s}$, respectively. The cumulative number of evacuees is shown in Fig. 6, and the green and red solid lines represent the time cost by the elevator door opening and closing on the 10th floor, respectively. The time to open and close the door of the elevator (TOC for short) on the 10th floor for the first trip was $18 \mathrm{~s}$ because of overload; for the second trip, it was $8 \mathrm{~s}$.

The elevator evacuation time for the first trip was $80 \mathrm{~s}$, shorter than the evacuation time when using stairs; however, the evacuation time for the second trip was longer than that when using stairs. As a result, elevators should be used at an early stage of evacuation.

The results of the post-experiment questionnaires are shown in Table 2. Most evacuees $(82.2 \%)$ felt anxious during experiment 1 , and they tried to move quickly according to the videos. Twelve evacuees reported that they used the elevator, 


\section{Table 3}

\section{Results of Questionnaire 2}

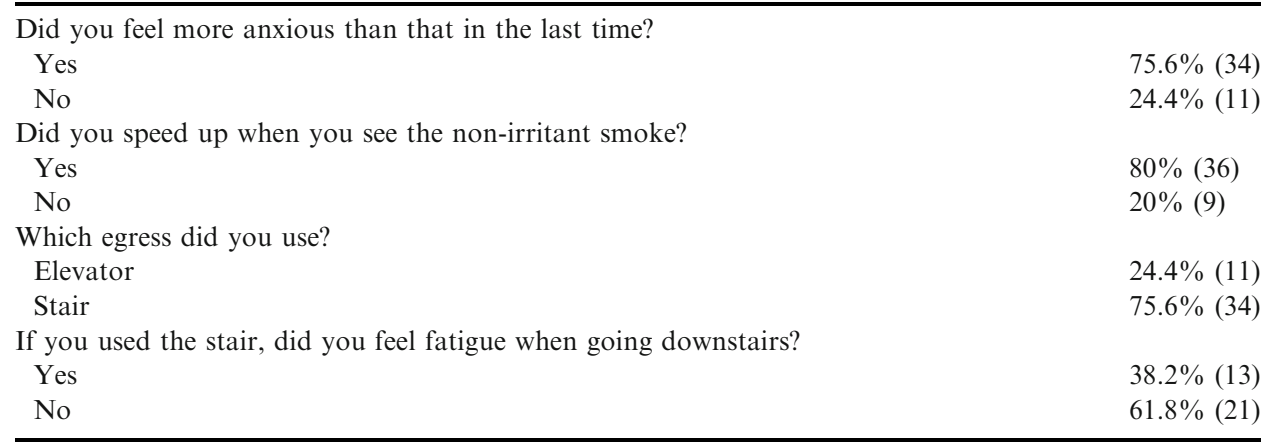

\section{Table 4}

\section{Results of Questionnaire 3}

\begin{tabular}{ll}
\hline Which one did you think that can influence your decision making on stairs or elevators? & \\
Explanation & $73.3 \%(33)$ \\
Experience & $26.7 \%(12)$ \\
Neither of them & $0 \%(0)$ \\
Which egress did you use? & $40 \%(18)$ \\
Elevator & $60 \%(27)$ \\
Stair & $37 \%(10)$ \\
If you used the stair, did you feel fatigue when going downstairs? & $63 \%(17)$ \\
Yes & No \\
\hline
\end{tabular}

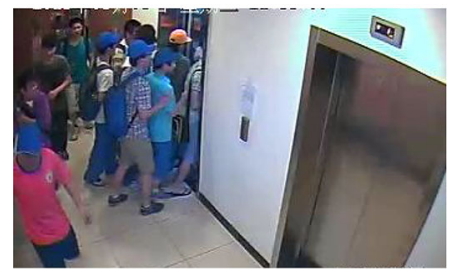

a

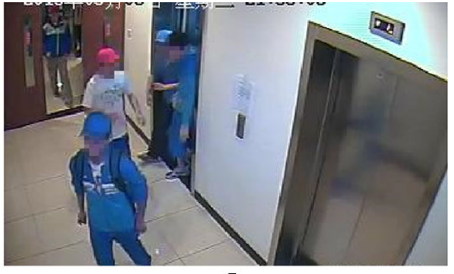

b

\section{Figure 5. Photographs of experiment 1.}

which is the same as demonstrated on the video. Rapid travel was the main reason for using the elevator. Participants cited two reasons for choosing to use the stairs: (1) they thought the elevator was not safe enough, and (2) they could not enter the elevator car and did not want to wait for another trip. In this experiment, about $40 \%$ of evacuees who used the stairs reported fatigue during the evacuation. 


\section{Table 5}

Waiting Times of Evacuees in Experiment 1

\begin{tabular}{lcc}
\hline ID & Waiting time (s) & Used the elevator? \\
\hline Trip 1 & & \\
1 & 27 & Yes \\
2 & 24 & Yes \\
3 & 20 & Yes \\
4 & 20 & Yes \\
5 & 12 & Yes \\
6 & 12 & Yes \\
7 & 7 & Yes \\
8 & 5 & Yes \\
9 & 1 & Yes \\
10 & 1 & Yes \\
11 & 0 & No \\
12 & 0 & No \\
13 & 0 & No \\
Trip 2 & & \\
1 & 74 & Yes \\
2 & 70 & Yes \\
\hline
\end{tabular}

\section{Table 6}

Waiting Times of Evacuees in Experiment 2

\begin{tabular}{lcc}
\hline ID & Waiting time (s) & Use elevator? \\
\hline Floor 10 & & \\
1 & 47 & Yes \\
2 & 47 & Yes \\
3 & 47 & Yes \\
4 & 45 & Yes \\
5 & 43 & Yes \\
6 & 37 & No \\
7 & 33 & Yes \\
8 & 28 & Yes \\
9 & 28 & No \\
10 & 26 & No \\
11 & 25 & No \\
12 & 24 & No \\
13 & 17 & No \\
14 & 8 & No \\
15 & 4 & No \\
16 & 3 & No \\
Floor 11 & & \\
1 & 4 & Yes \\
2 & 3 & Yes \\
3 & 1 & Yes \\
\hline
\end{tabular}




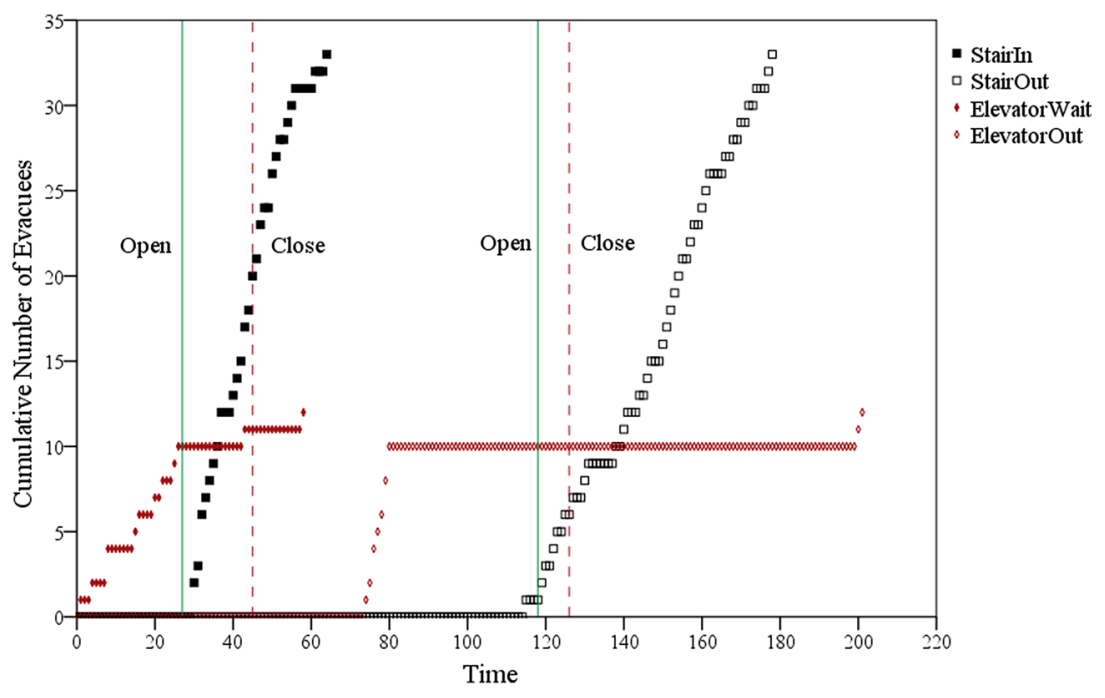

Figure 6. Results of experiment 1.

According to the questionnaire (see Fig. 3), 55.6\% of participants wanted to use the elevator on the 10th floor. In the experiment, only $26.7 \%$ of them used the elevator, and about $40 \%$ tried to wait for it. The results of the questionnaire and experiment were therefore inconsistent; that is, people appeared to make decisions according to their immediate environment and psychological state.

\subsection{Results of Experiment 2}

In experiment 2, harmless non-irritant smoke was released without informing the participants, and the participants were not aware that this was going to happen beforehand. Photographs from experiment 2 are shown in Fig. 7. Figure 8a shows that the first participant pressed the elevator call button. He did not want to wait for the elevator in the non-irritant smoke condition, so he chose to use the stairs (see Fig. 7b) after about $3 \mathrm{~s}$. In this experiment, 11 people used the elevator and 34 people used the stairs. The elevator made one evacuation trip to pick up evacuees, and an interesting phenomenon occurred: many evacuees tried to enter the car from other floors, although we positioned one person on each floor except the

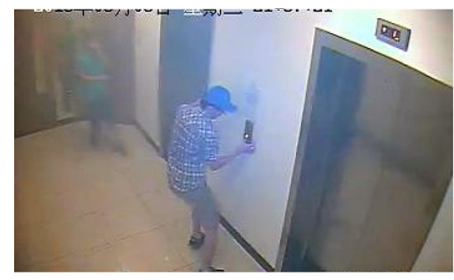

a

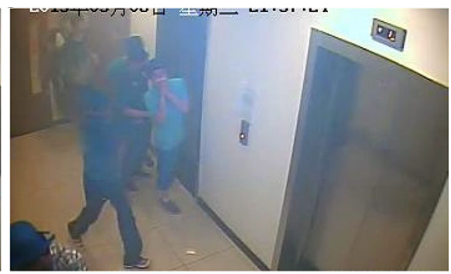

b

Figure 7. Photographs of experiment 2. 


\section{Table 7}

Waiting Times of Evacuees in Experiment 3

\begin{tabular}{lcc}
\hline ID & Waiting time (s) & Use elevator? \\
\hline Trip 1 & 31 & \\
1 & 31 & Yes \\
2 & 31 & Yes \\
3 & 30 & Yes \\
4 & 19 & Yes \\
5 & 19 & Yes \\
6 & 15 & Yes \\
7 & 15 & Yes \\
8 & 11 & Yes \\
9 & 5 & Yes \\
10 & 5 & Yes \\
11 & 1 & Yes \\
12 & 1 & Yes \\
13 & 15 & No \\
Trip 2 & & \\
1 & 74 & Yes \\
2 & 74 & Yes \\
3 & 73 & Yes \\
4 & 72 & Yes \\
5 & 72 & Yes \\
6 & 71 &
\end{tabular}

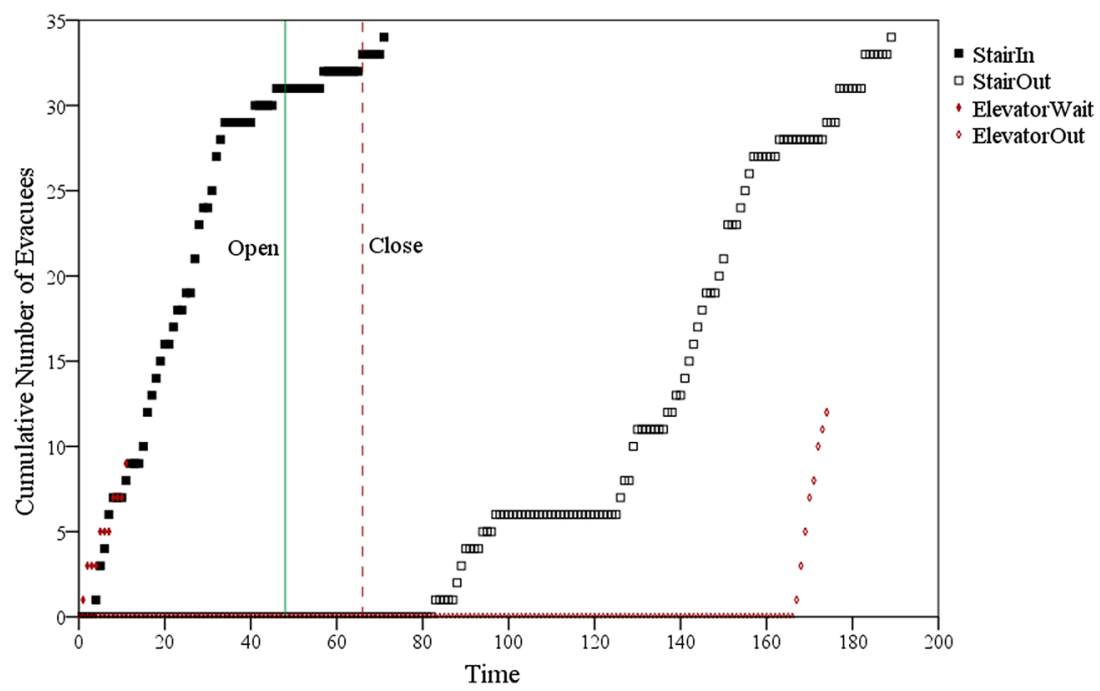

\section{Figure 8. Results of experiment 2.}

10th to prevent people from using the elevator. Our staff told participants, "Please do not use the elevator on this floor." However, some participants did not follow 


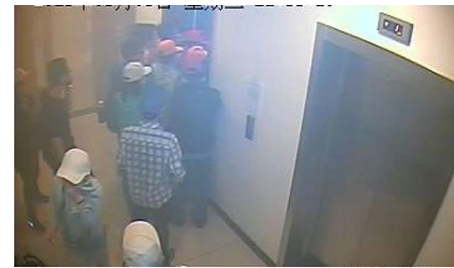

a

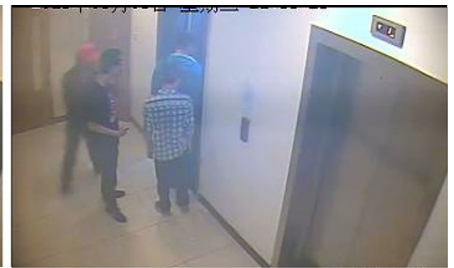

b

Figure 9. Photographs of evacuees entering the car in experiment 2.

directions, perhaps because the non-irritant smoke made them anxious. This phenomenon may happen in a real-life elevator evacuation as well. Among the evacuees who used the elevator, three of them entered the car on the 11th floor (they went up one floor using the stairs), and the rest entered the car on the 10th floor. Fourteen evacuees tried to enter the car on the 10th floor, but only nine used the elevator for evacuation. The number of waiting evacuees was similar to that in experiment 1 . The wait times of the participants who used the elevator is shown in Table 6. Many participants arrived at the elevator room early, but they did not want to use the elevator because they crossed through the non-irritant smoke. After the elevator left, no one wanted to wait for the second trip. Judging from the proportion of elevator use and number of elevator trips, the non-irritant smoke influenced participants' decision to use the stairs or the elevator. In this experiment, eight evacuees chose to use the stairs.

The stair evacuation and elevator evacuation times in experiment 2 were $189 \mathrm{~s}$ and $174 \mathrm{~s}$, respectively, as shown in Fig. 8. Although the participants were moving faster in the non-irritant smoke condition according to the questionnaire (see Table 3), in which $80 \%$ of the evacuees stated they sped up, the stair evacuation time was longer than in experiment 1 . This may be because evacuees who used the stairs tried to press the hall call buttons on other floors for they wanted to wait for the elevator on these floors. Compared with the elevator evacuation time of the first trip in experiment 1, which for experiment 2 was $98 \mathrm{~s}$ longer because the elevator stopped at nearly every floor below the 10th floor. According to interviews after the experiments, the participants said they just wanted to try to use the elevator on other floors because they thought they could evacuate more quickly via elevator; thus, elevator control is crucial during elevator evacuations. The
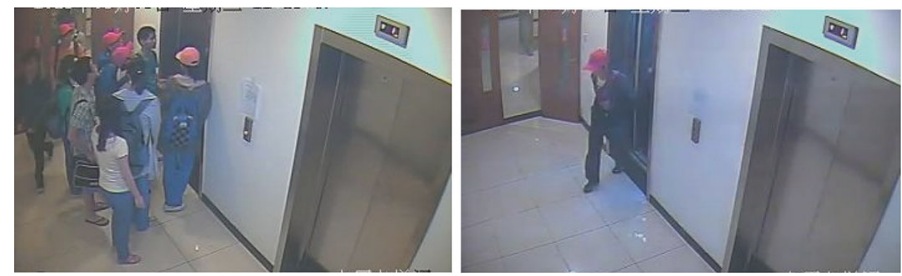

Figure 10. Photographs of experiment 3. 


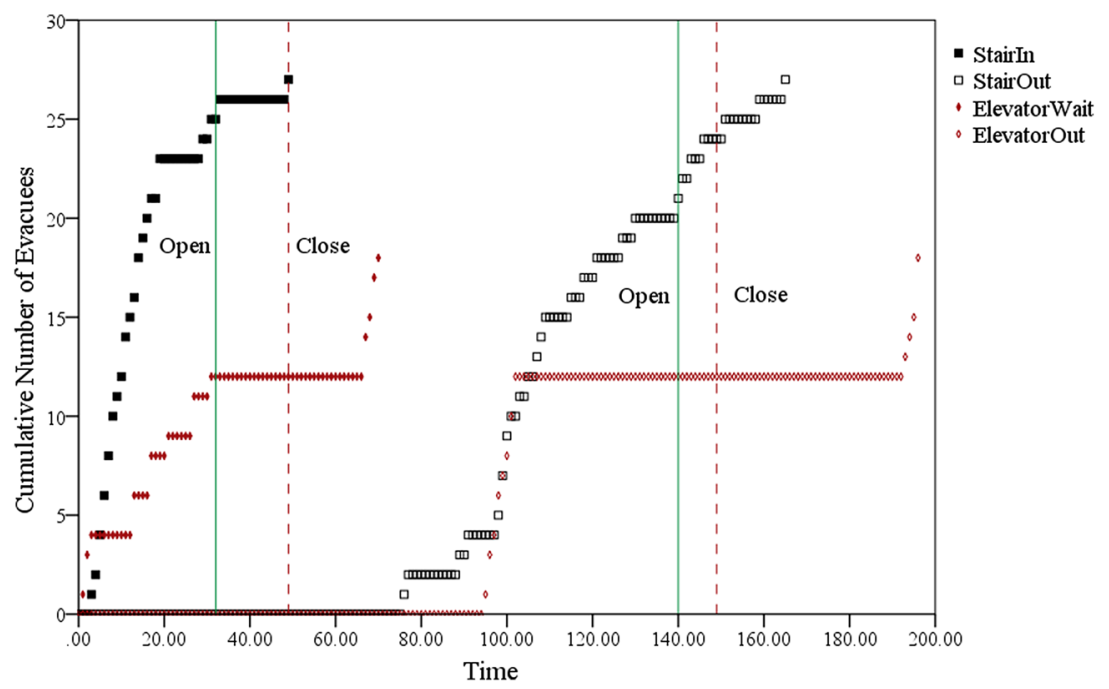

\section{Figure 11. Results of experiment 3.}

cumulative number of evacuees is shown in Fig. 8. The green and red solid lines represent the time it took for the elevator door to open and close, respectively, on the 10th floor. The TOC on the 10th floor for the first trip was $20 \mathrm{~s}$ because of overload, and Fig. 9a shows that the evacuees entered the car.

According to the questionnaire (see Table 3), most evacuees $(75.6 \%$ ) felt more anxious than in experiment 1 , and $80 \%$ of them tried to move faster. Eleven evacuees used the elevator, the same as shown in the videos. Among evacuees who used the stairs, $38.2 \%$ felt fatigued during experiment 2 .

\subsection{Results of Experiment 3}

In experiment 3, harmless non-irritant smoke was also released. In this experiment, 18 people used the elevator and 27 used the stairs (see photographs in Fig. 10). The elevator traveled two trips to pick up evacuees. During the first trip, 13 evacuees tried to enter the car, 12 of whom used the elevator to evacuate. During the second trip, six participants used the elevator, and they were waiting for more than $70 \mathrm{~s}$. The wait times for participants who used the elevator are shown in Table 7. The average wait time for the second trip was $40 \mathrm{~s}$ longer than for the first trip. In this experiment, more people used the elevator than in other experiments ( $45 \%$ more than in experiment 2). Four evacuees opted to use the stairs.

The stair evacuation and elevator evacuation times for experiment 3 were $165 \mathrm{~s}$ and $196 \mathrm{~s}$, respectively. The results of experiment 3 appear in Fig. 11. The stair evacuation was faster than in the other experiments. The cumulative number of evacuees is shown in Fig. 11, and the green and red solid lines represent the times the elevator door opened and closed at the elevator room, respectively, on the 10th floor. The TOC on the 10th floor for the first trip was $17 \mathrm{~s}$ and $9 \mathrm{~s}$ for the second trip. According to the results of our experiments and questionnaires, 
knowledge of an evacuation plan can influence evacuees' choice of stairs or the elevator. The maximum capacity of experiments 1,2 , and 3 was 10 persons, 11 persons, and 12 persons, respectively. The potential number of elevator users in these experiments was $20(10 \times 2$ trips $), 11(11 \times 1$ trip $)$, and $24(12 \times 2$ trips $)$, respectively.

\subsection{Evacuation Phenomena}

Several phenomena were observed in these experiments:

(1) Social bonds Evacuees with social bonds tended to use the elevator or stairs together. Interestingly, two people used the elevator together in each experiment. After the experiments, we found out the people were a couple based on an after-experiment interview. The man tried to push the woman into the car when the elevator door opened, and neither wanted to get out of the car when the car was overloaded. This phenomenon is highly likely in a real elevator evacuation, especially if some evacuees are socially bonded [44, 45].

(2) Hesitation Evacuees were unsure of whether to use the elevator or the stairs, and they slowed down or stopped moving when making their final decision. The space in front of the elevator was limited in the building (see Fig. 1) where we held the experiments, and evacuees blocked the pedestrian flow when they slowed down or stopped. As a result, in the event of an evacuation,

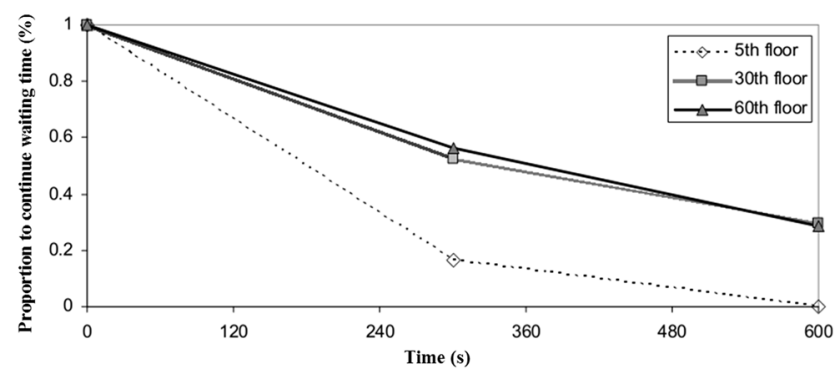

(a) Elevator waiting time in Heyes's work [6].
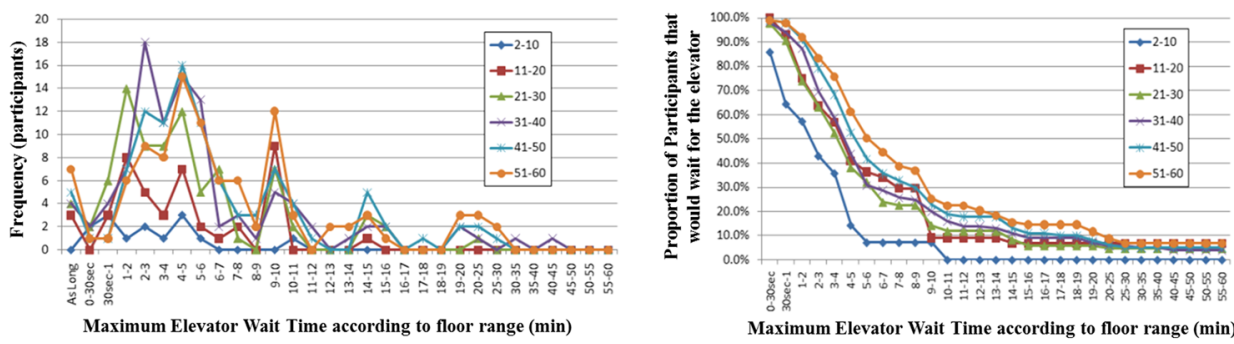

(b) Elevator waiting time in Kinsey's work.

Figure 12. Proportion of waiting time on different floor levels in the references [6, 41 ]. 


\section{Table 8}

Percentage of Waiting Time in Experiment 1

\begin{tabular}{lllllll}
\hline Range (second) & $1-5$ & $6-15$ & $16-30$ & $31-45$ & $46-60$ & $61-75$ \\
Number of evacuees & 3 & 3 & 4 & 0 & 0 & 2 \\
Cumulative number & 12 & 9 & 6 & 2 & 2 & 2 \\
Percentage (\%) & 100 & 75 & 50 & 16.7 & 16.7 & 16.7 \\
\hline
\end{tabular}

\section{Table 9}

\section{Percentage of Waiting Time in Experiment 2}

\begin{tabular}{llllll}
\hline Range (second) & $1-5$ & $6-15$ & $16-30$ & $31-45$ & $46-60$ \\
Number of evacuees & 5 & 1 & 6 & 4 & 3 \\
Cumulative number & 19 & 14 & 13 & 7 & 3 \\
Percentage (\%) & 100 & 73.7 & 68.4 & 36.8 & 15.8 \\
\hline
\end{tabular}

\section{Table 10}

\section{Percentage of Waiting Time in Experiment 3}

\begin{tabular}{|c|c|c|c|c|c|c|}
\hline Range (s) & $1-5$ & $6-15$ & $16-30$ & $31-45$ & $46-60$ & $61-75$ \\
\hline Number of evacuees & 4 & 3 & 3 & 3 & 0 & 6 \\
\hline Cumulative number & 19 & 15 & 12 & 9 & 6 & 6 \\
\hline Percentage $(\%)$ & 100 & 78.9 & 63.2 & 47.4 & 31.6 & 31.6 \\
\hline
\end{tabular}

evacuees should be picked up by elevators in a large space that is connected to exit stairs $[2,26]$.

(3) Elevator exit Evacuees exited the car one by one when the car was overloaded. When evacuees heard the alarm signaling overload, they did not know how many should exit the car. They got out of the car one by one (except those with social bonds) until the alarm stopped.

(4) Fatigue After traveling 5 (20 m vertically) to 8 (32 m vertically) floors using the stairs, some evacuees felt fatigued; this phenomenon was also reported in the evacuation of the World Trade Center on September 11th, 2001 [27].

\subsection{Comparison with Other Studies}

Participants' wait time tolerance on different floors in the survey by Heyes [6] and Kinsey [41] is shown in Fig. 12. In Ref. [6], 138 persons participated in the online survey. In these cases, the buildings were office buildings with 5 floors, 30 floors, and 60 floors. In Ref. [41], 468 persons participated in the online survey, and they were asked whether they wanted to use the elevators on different floors. However, the wait times in our experiments (see Tables 8, 9, and 10) were considerably different from those reported in the earlier observations. In our study, most evacuees did not want to wait for the elevator for more than 1 min based on the scenario 
and environment. Thus, the results of questionnaires and online surveys do not always represent participants' true intentions as, in our case, participants were not involved in a real evacuation.

\subsection{Limitations}

There is a gap between experiments and real fire emergency events. The environment of our experiments was not identical to a real fire event: there was no fire and no real smoke in the air. In most buildings where elevators can be used for evacuation, elevator waiting areas are enclosed in fire-rated construction, and they are pressurized to prevent smoke ingress. In addition, most evacuation strategies would not require people to use the lift on the fire floor; rather, people would move to another floor before using an elevator to evacuate. The experiments in our paper were carried out under special circumstances where the fire ventilation system had failed. If escalators were used in the experiments, they might affect the number of evacuees using the elevator.

Participants were getting familiar with the building after each experiment since the participants were the same in the three experiments. The participants were more familiar with they cannot use the elevators during evacuation. In the experiments, they were allowed to use only one stairwell or one elevator, and there was no path finding problem. The familiarity of evacuation route cannot influence participants much, however, the familiarity of using elevators would influence them a lot. In experiment 1, they used the elevator for the first time. In experiment 2, smoke was released, and they were stressful to evacuate. Then they were told about the knowledge of elevator evacuation and how long will the elevator arrive at the tenth floor. In experiment 3, they did experiment 2 again. From experiment 2 to 3 , both their evacuation experience and the knowledge may influence their behaviors. The purpose of giving them knowledge is to let them get more experience of evacuation. In experiment 2, participants used the elevator outside of Floor 10. Although this uncertain phenomenon is a part of the experiment results, it is a loss of experimental control in experiment 2 to some extent. This limit affected the comparison among the experiments. As a result, we only compared the proportion of population who used the elevator.

The participants in our experiments were all Chinese students and well-educated; the type of participants and Chinese culture may have influenced the experimental results. A few participants carried bags during the evacuation, which may have had a minor impact on the elevator's load. Age and gender were not considered in this paper, nor were people with mobility impairments. Furthermore, we identified a gap between the results of our questionnaires and those of our experiments; it is difficult to capture what participants were truly thinking during the evacuation. Finally, the sample size was small: the conclusions of this paper are based on three experiments with 45 participants, and more data is needed in future studies on this topic. 


\section{Conclusion}

Experiments were carried out to study evacuees' behavior around the combined use of an elevator and stairs during a high-rise building evacuation. Non-irritant smoke and knowledge of evacuation procedures were found to influence evacuees' behavior and choice of using the elevator or stairs. In experiment 1, 26.7\% of 45 participants chose the elevator. In experiment 2, non-irritant smoke was released, and the proportion of participants who used the elevator decreased to $24.4 \%$ of 45 participants. Before experiment 3, participants were provided some information about the evacuation procedure (i.e., education or explanation about the evacuation and elevator evacuation experience), after which the proportion of elevator use increased to $40 \%$. As a result, we found that non-irritant smoke influenced evacuees' behavior, and knowledge of evacuations in particular affected evacuees' behavior and choice to use the elevator or stairs. In result, when designing stair and elevator evacuation plans in a high-rise building, occupants' prior knowledge should be considered. Finally, several suggestions are given to building designers, and basic data (such as evacuation time and proportion of people using the stairs or elevator) can provide insight for building safety engineers into evacuation strategies that include stairs and elevators.

These experiments also substantiate conclusions from various studies: evacuation elevators should be used on certain floors (such as refuge floors) instead of on every floor [8,9]. For example, evacuees tried to use the elevator on nearly every floor in experiment 2 , which delayed the elevator evacuation time and disturbed pedestrian flow in the stairway. Additionally, we noted a gap between the results of questionnaires (or online surveys) and the results of experiments (or evacuation events); that is, how people actually behave is more important than how they intend to behave. In our future work, more factors should be tested experimentally, such as social influence [30] or social bonds, floor levels, and immediate evacuation guidance.

\section{Acknowledgements}

This work is supported by National Key R\&D Program of China (No. 2017YFC0803300), the Fundamental Research Funds for the Central Universities (No. 2019JKF212), the National Natural Science Foundation of China (Nos. $71373139,91646201)$.

\section{Open Access}

This article is distributed under the terms of the Creative Commons Attribution 4.0 International License (http://creativecommons.org/licenses/by/4.0/), which permits unrestricted use, distribution, and reproduction in any medium, provided you give appropriate credit to the original author(s) and the source, provide a link to the Creative Commons license, and indicate if changes were made. 


\section{References}

1. Council IC, Cod I (2015) International Building Code

2. National Fire Protection Association (2011) NFPA 101 life safety code. National Fire Protection Association, Quincy

3. National Fire Protection Association (2012) Building construction and safety code. National Fire Protection Association, Quincy

4. BSI BS (2008) 9999 Code of practice for fire safety in the design, management and use of buildings, BSI Global, London

5. Kinsey MJ, Galea ER, Lawrence PJ (2012) Human factors associated with the selection of lifts/elevators or stairs in emergency and normal usage conditions. Fire Technol 48(1):3-26

6. Heyes E (2009) 'Human behavior considerations in the use of lifts for evacuation from high-rise commercial buildings', Master thesis, University of Canterbury, Department of Civil Engineering

7. Kinsey MJ, Galea ER, Lawrence PJ (2009) Investigating the use of elevators for highrise building evacuation through computer simulation, Proceedings of the human behavior in fire conference, pp 85-96

8. Proulx G, Johnson P, Heyes E, Hedman G, Averill J, Pauls J, McColl D (2009) 'The use of elevators for egress: discussion panel', Proceedings of human behaviour in fire conference, pp 97-110

9. Ronchi E, Nilsson D (2013) Fire evacuation in high-rise buildings: a review of human behaviour and modelling research. Fire Sci Rev 2(1):7

10. Tancogne-Dejean M, Laclémence P (2016) Fire risk perception and building evacuation by vulnerable persons: points of view of laypersons, fire victims and experts. Fire Saf $\mathbf{J}$ 80:9-19

11. Helbing D, Farkas IJ, Molnar P et al (2002) Simulation of pedestrian crowds in normal and evacuation situations. Pedestr Evacuation Dyn 21(2):21-58

12. Mcconnell NC, Boyce KE (2015) Refuge areas and vertical evacuation of multistorey buildings: the end users' perspectives. Fire Mater 39(4):396-406

13. Averill J, Mileti D, Peacock R, Kuligowski E, Groner N, Proulx G, Reneke P, Nelson $\mathrm{H}$ (2005) 'Federal building and fire safety investigation of the world trade center disaster-occupant behavior, egress and emergency communications', NIST NCSTAR 1-7. US Government Printing Office, Washington

14. Howkins R. (2000) In the event of fire - use elevators. In: Proceedings of ELEVCON 2000, Elevator Technology 10, pp 11-21

15. Proulx G, Pineau J, Latour JC, Stewart L (1995) Study of the occupants behaviour during the 2 forest laneway fire in North York, Ontario, January 6, I995, Internal Report: IRC-IR-705

16. Proulx G, Reid I, Cavan N (2004) 'Human behavior study-cook county administration building fire October 17, 2003 Chicago Illinois', Research Report No. 181. National Research Council Canada, Ottawa

17. Sekizawa A, Ebihara ME, Notake H, Kubota K, Nakano M, Ohmiya Y, Kaneko H (1999) Occupants behaviour in response to the high-rise apartments fire in Hiroshima city. In: Proceedings of human behaviour in fire, pp 297-303

18. Nilsson D, Jonsson A (2011) Design of evacuation systems for elevator evacuation in high-rise buildings. J Disaster Res 6(6):600-609

19. ASME/A17 (2013) Safety code for elevators and escalators. Task groups on use of elevators by firefighters and use of elevators for occupant egress. American Society of Mechanical Engineers, New York 
20. Klote JH, Alvord DM, Levin BM, Groner NE (1992) Feasibility and design considerations of emergency evacuation by elevators, NISTIR 4870National Institute of Standards and Technology, Gaithersburg, p. 126

21. Kuligowski ED, Bukowski RW (2004) Design of occupant egress systems for tall buildings, use of elevators in fires and other emergencies workshop. In: Proceedings, 2-4 March 2004. Co-sponsored by American Society of Mechanical Engineers (ASME International); National Institute of Standards and Technology (NIST); International Code Council (ICC); National Fire Protection Association (NFPA); U.S. Access Board and International Assn of Fire Fighters (IAFF), Atlanta pp 1-12

22. Fang Zhi-Ming, Song Wei-Guo, Li Zi-Juan, Tian Wei, Lv Wei, Ma Jian, Xiao Xia (2012) Experimental study on evacuation process in a stairwell of a high-rise building. Build Environ 47:316-321

23. Xu X, Song W (2009) Staircase evacuation modeling and its comparison with an egress drill. Build Environ 44(5):1039-1046

24. Bukowski R (2005) 'Protected elevators for egress and access during fires in tall buildings', workshop on building occupant movement during fire emergencies, pp 14-21

25. Bukowski, R. W. (2010) Applications of elevators for occupant egress in fires, Fire Protect Eng 38

26. Weismantle P, Smith G, Sheriff M (2007) Burj Dubai: an architectural technical design case study. Struct Design Tall Spec Build 16:335-360

27. Galea ER, Hulse L, Day R et al (2009) The UK WTC 9/11 evacuation study: an overview of the methodologies employed and some analysis relating to fatigue, star travel speeds and occupant response

28. Lee D, Park JH, Kim H (2004) A study on experiment of human behavior for evacuation simulation. Ocean Eng 31(8):931-941

29. Ma J, Song WG, Tian W, Lo SM, Liao GX (2012) Experimental study on an ultra high-rise building evacuation in China. Saf Sci 50(8):1665-1674

30. Nilsson D, Johansson A (2009) Social influence during the initial phase of a fire evacuation - analysis of evacuation experiments in a cinema theatre. Fire Saf J 44(1):71-79

31. Fang Z, Song W, Zhang J et al (2010) Experiment and modeling of exit-selecting behaviors during a building evacuation. Physica A Stat Mech Appl 389(4):815-824

32. Zhang J, Klingsch W, Schadschneider A, Seyfried A (2011) Transitions in pedestrian fundamental diagrams of straight corridors and T-junctions. J Stat Mech . https:// doi.org/10.1088/1742-5468/2011/06/p06004

33. Kretz T, Grünebohm A, Kaufman M, Mazur X, Schreckenberg M (2006) Experimental study of pedestrian counterflow in a corridor. J Stat Mech . https://doi.org/10.1088/ $1742-5468 / 2006 / 10 / \mathrm{p} 10001$

34. Guo RY, Huang HJ, Wong SC (2013) A potential field approach to the modeling of route choice in pedestrian evacuation. J Stat Mech . https://doi.org/10.1088/1742-5468/ 2013/02/p02010

35. Kretz T, Grünebohm A, Schreckenberg M (2006) Experimental study of pedestrian flow through a bottleneck. J. Stat. Mech. 10014(5):P10014

36. Liao W, Seyfried A, Zhang J, Boltes M, Zheng X, Zhao Y (2014) Experimental study on pedestrian flow through wide bottleneck, the conference on pedestrian and evacuation dynamics 2014 (PED 2014), 22-24 October 2014, Delft, The Netherlands, Volume 2, Pages 26-33

37. Zhang J, Seyfried A (2014) Quantification of bottleneck effects for different types of facilities, the conference on pedestrian and evacuation dynamics 2014 (PED 2014), 22 24 October 2014, Delft, The Netherlands, Volume 2, Pages 51-59 
38. Liao YJ, Lo SM, Ma J et al (2014) A study on people's attitude to the use of elevators for fire escape. Fire Technol 50(2):363-378

39. Bukowski RW (2012) Addressing the needs of people using elevators for emergency evacuation. Fire Technol 48(1):127-136

40. Butry DT, Chapman RE, Huang AL et al (2012) A life-cycle cost comparison of exit stairs and occupant evacuation elevators in tall buildings. Fire Technol 48(2):155-172

41. Kinsey MJ (2011) Vertical transport evacuation modelling. University of Greenwich, London

42. Pauls J (1994) Vertical evacuation in large buildings: missed opportunities for research. DISASTER MANAGEMENT-REDHILL- 6:128

43. Maister DH (1984) The psychology of waiting lines. Harvard Business School, Boston

44. Ding N, Chen T, Zhang H (2017) Experimental study of elevator loading and unloading time during evacuation in high-rise buildings. Fire Technol 53(1):29-42

45. von Krüchten C, Müller F, Svachiy A et al (2016) Empirical study of the influence of social groups in evacuation scenarios. Traffic and Granular Flow'15. Springer International Publishing, Cham, pp. 65-72

Publisher's Note Springer Nature remains neutral with regard to jurisdictional claims in published maps and institutional affiliations. 